\title{
Hemodynamic Changes During Heart Displacement in Aorta No-Touch Off-Pump Coronary Artery Bypass Surgery: A Pilot Study
}

Alexandre R. Carvalho ${ }^{1,2}$, MD; Solange Guizilini ${ }^{3}, \mathrm{PT}, \mathrm{PhD}$; Gustavo M. Murai ${ }^{1,2}, \mathrm{CCP}$; Isis Begot ${ }^{3}$, PT, MSc; Isadora S. Rocco $^{3}$, PT, MSc; Nelson A. Hossne Jr³, MD, PhD; Eduardo G. Chamlian ${ }^{1,2}$, MD, MSc; João Manoel T. Santos ${ }^{1}$, MD, PhD; Ricardo A. Macedo', MD; Gustavo C.O. Lisboa', MD; Alberto C. Nasciutti' ${ }^{1}$, MD; Carlos Eduardo R. Santos' ${ }^{1}$, MD; João Paulo M. Figueiredo', MD; Walter J. Gomes ${ }^{1,2,3}$, MD, PhD

DOI: 10.21470/1678-9741-2018-0090

\section{Abstract}

Objective: To evaluate the sequential changes of hemodynamic and metabolic parameters in patients who underwent aorta notouch off-pump coronary artery bypass surgery (OPCAB).

Methods: Prospective study involving twenty-seven consecutive patients who underwent aorta no-touch OPCAB. The FloTrac/PreSep/Vigileo ${ }^{\text {TM }}$ system (Edwards Lifesciences) was used to continuously record heart rate (HR), mean arterial blood pressure (MABP), central venous pressure (CVP), continuous cardiac index $(\mathrm{FCl})$, stroke volume (SV), stroke volume variation (SVV), and central venous oxygen saturation $\left(\mathrm{ScvO}_{2}\right)$. The parameters were assessed 5 min before, during and 5 min after each anastomosis (left anterior descending [LAD], posterior descending [PD], obtuse marginal [OM] and diagonal [Dg]). Postoperative lactate was also evaluated.

Results: There was no significant change in HR and MABP for all anastomoses, except for MABP during PD grafting $(-10.1 \pm 2.7$ $\mathrm{mmHg}, P=0.03)$. There was a significant decrease in $\mathrm{ScvO}_{2}$ only during $P D$ and $O M$ anastomoses $(-9.4 \pm 0.4, P=0.03 ;-4.4 \pm 0.4, P=0.02$; respectively). CVP drop after PD manipulation was strongly associated with a higher lactate during the first hours after surgery $(r=-0.82 ; P=0.001)$. These hemodynamic changes were transient and entirely recovered after the heart was returned to its anatomical position. No significant differences were observed in $\mathrm{FCl}, \mathrm{SVV}$, or the systemic vascular resistance index (SVRI) during all anastomoses, except for a drop in SVRI during PD grafting $(-8.03 \pm 2.3, P=0.007)$. SV tended to decrease during the procedure in all territories, but with statistically significant drop only in PD and OM grafting $(-10.4 \pm 1.2, P=0.02 ;-13.6 \pm 5.1, P=0.007$; respectively).

Conclusion: Heart displacement for performing aorta notouch OPCAB is well tolerated, with transient and endurable hemodynamic variations.

Keywords: Coronary Artery Bypass. Coronary Artery Bypass, Off-Pump. Stroke. Intracranial Embolism. Hemodynamics.

\begin{tabular}{llll}
\hline \multicolumn{2}{l}{ Abbreviations, acronyms \& symbols } & & \\
\hline CABG & $=$ Coronary artery bypass grafting & LVEF & $=$ Left ventricular ejection fraction \\
CCO & $=$ Continuous cardiac output & MABP & $=$ Mean arterial blood pressure \\
CO & $=$ Cardiac output & OM & $=$ Obtuse marginal \\
CVP & $=$ Central venous pressure & OPCAB & $=$ Off-pump coronary artery bypass surgery \\
Dg & $=$ Diagonal & PCI & $=$ Percutaneous coronary intervention \\
ECG & $=$ Electrocardiogram & PD & $=$ Posterior descending \\
FCI & $=$ Continuous cardiac index & RITA & $=$ Right internal thoracic artery \\
HR & $=$ Heart rate & SCvO & $=$ Central venous oxygen saturation \\
ITAs & $=$ Internal thoracic arteries & SV & $=$ Stroke volume \\
LAD & $=$ Left anterior descending & SVRI & $=$ Systemic vascular resistance index \\
LITA & $=$ Left internal thoracic artery & SVV & $=$ Stroke volume variation \\
LV & $=$ Left ventricle & & \\
\hline
\end{tabular}

'Policlin Hospital, São José dos Campos, SP, Brazil.

2Pirajussara General Hospital/SPDM and Clinics Hospital Luzia de Pinho Melo/ SPDM, São Paulo, SP, Brazil.

${ }^{3}$ Discipline of Cardiovascular Surgery, Escola Paulista de Medicina and São Paulo Hospital - Universidade Federal de São Paulo (Unifesp), São Paulo, SP, Brazil.

This study was carried out at the Discipline of Cardiovascular Surgery, Escola Paulista de Medicina, Universidade Federal de São Paulo (Unifesp), São Paulo, SP, Brazil and at Policlin Hospital, São José dos Campos, SP, Brazil.

This paper was presented at the $44^{\text {th }}$ Congress of the Brazilian Society of Cardiovascular Surgery, Rio de Janeiro, RJ, Brazil, April 20-22, 2017.
No financial support.

No conflict of interest.

Correspondence Address:

Walter J Gomes

Rua Borges Lagoa 1080, cj 608 - Vila Clementino - São Paulo, SP, Brazil Zip Code: 04038-002

E-mail:wjgomes1012@gmail.com 


\section{INTRODUCTION}

The aorta no-touch off-pump coronary artery bypass surgery $(\mathrm{OPCAB})$ has been the recommended technique for treatment of patients with high risk for neurological damage or stroke ${ }^{[1]}$. The concept stems from avoiding any ascending aorta manipulation, virtually eliminating the risk of embolism of aortic wall debris into the brain circulation, utilizing the off-pump beating heart surgery technique ${ }^{[2]}$. However, the displacement of the heart to achieve suitable exposure for graft construction elicits hemodynamic changes, potentially requiring conversion to on-pump surgery and increasing morbimortality risk ${ }^{[3]}$. Early detection of premonitory hemodynamic alterations leading to conversion may help avert this dreadful complication.

The FloTrac/PreSep/Nigileo ${ }^{\mathrm{TM}}$ system (Edwards Lifesciences, Irvine, (A, USA) is a less invasive monitoring device allowing continuous determination of cardiac output (CO) and other hemodynamic variables using pulse wave analysis, coupled with mixed central venous oxygen saturation $\left(\mathrm{ScvO}_{2}\right)$ assessment ${ }^{[4]}$.

Therefore, the aim of this study was to evaluate the sequential changes of hemodynamic variables during coronary artery anastomoses in patients who underwent aorta no-touch OPCAB using the FloTrac/PreSep/Vigileo ${ }^{\mathrm{TM}}$ system.

\section{METHODS}

This prospective study enrolled twenty-seven consecutive

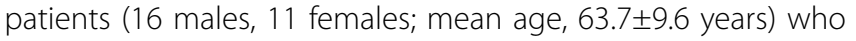
underwent elective first-time aorta no-touch OPCAB. After the Institutional Ethical Committee's approval, informed consent was obtained from all the patients. All operations were performed by a single surgeon (WJG) to eliminate technical variability.

In the operating room, electrocardiogram (ECG) leads were monitored, the radial artery was cannulated for continuous monitoring of arterial blood pressure and blood gas analysis and connected to a FloTrac ${ }^{\mathrm{TM}}$ pressure transducer. The PreSep ${ }^{\mathrm{TM}}$ central venous oximetry catheter was inserted through the right jugular vein, the Vigileo ${ }^{\mathrm{TM}}$ system was next loaded with the patient's demographic data, pressure was zeroed and set to display variables' measurement within the past 60 seconds.

Anesthetic technique was standardized for all patients. Anesthesia was induced with 2.0-3.0 mg of midazolam, 1.0-3.0 mg/ $\mathrm{kg}$ of sufentanil, and $50 \mathrm{mg}$ of rocuronium and it was maintained with $0.2-0.5$ vol\% of isoflurane and continuous intravenous infusion of $0.5-1.5 \mathrm{mg} / \mathrm{kg} / \mathrm{min}$ of sufentanil and vecuronium. Ventilation was controlled with oxygen-air mixture $\left(\mathrm{FiO}_{2}\right.$ 0.6) to maintain end-tidal $\mathrm{CO}_{2}$ in $35-38 \mathrm{mmHg}$. For preventing hypothermia, the operating room's temperature was maintained above $24^{\circ} \mathrm{C}$ and the patients were continuously rewarmed with warm mattress. After median sternotomy, the internal thoracic arteries (ITAs) were taken-down from the inner chest wall in skeletonized fashion and heparin was given to attain activated clotting time $>250 \mathrm{seg}$. After pericardial longitudinal opening, the heart was inspected, and pericardial stay sutures were placed, deeper in the left side than in the right. Additionally, one or two deep pericardial stitches were placed close to the left inferior pulmonary vein. All these sutures together, once forcefully pulled up, improved the exposure of the lateral and inferior aspects of the heart. The application of a suction-type tissue stabilizer (Octopus Tissue Stabilizer System, Medtronic Inc., Minneapolis, MN, USA) completed the task of a suitable exposure of the coronary arteries to be grafted. The left anterior descending (LAD) is the first coronary artery in the grafting sequence, followed by the posterior descending (PD), obtuse marginal $(\mathrm{OM})$, and diagonal (Dg) arteries. No distal coronary snaring, $\mathrm{CO}_{2}$ blower, or intra-coronary shunts were used in this series, in accordance with our usual OPCAB practice.

Hemodynamic stability was maintained, once necessary, with transitory use of inotropes (dobutamine infusion), vasopressors (noradrenaline), and volume expansion with crystalloid solutions. During graft anastomosis to OM and PD, patients were placed in the Trendelenburg position, and the table was rotated slightly to the right.

The OM was always revascularized using right internal thoracic artery (RITA) grafts (16/27), either in situ routed through the transverse sinus or as a free graft attached end-to-side to the left internal thoracic artery (LITA). The vein graft to PD was connected to the RITA's proximal stump (17/27). Figure 1.

All proximal grafts were attached to the ITAs, and the ascending aorta remained untouched throughout all the operations; most of the times, the pericardium over the aorta was not split to completely avert any aorta manipulation.

Protamine was administered to fully reverse the heparin effect after the completion of revascularization.

The FloTrac/PreSep/Vigileo system ${ }^{\text {TM }}$ (Edwards Lifesciences) was utilized to continuously record hemodynamic variables: heart rate $(\mathrm{HR})$, mean arterial blood pressure (MABP), central venous pressure (CVP), continuous cardiac index $(\mathrm{FCl})$, stroke volume (SV), stroke volume variation (SV), and $\mathrm{ScVO}_{2}$. The systemic vascular resistance index (SVRI) derived from collected parameters was calculated. The FloTrac ${ }^{\mathrm{TM}}$ system utilizes the radial artery line for analysis of the arterial waveform to calculate $\mathrm{CO}$ and other parameters derived from CO data. The PreSep ${ }^{\mathrm{TM}}$ central venous oximetry catheter provides a central venous line for volume administration and once connected to the Vigileo ${ }^{\mathrm{TM}}$ monitor, it allows continuous measurement of CVP and $\mathrm{ScVO}_{2}$.

The hemodynamic variables were assessed 5 minutes before the heart's displacement for anastomosis, during graft construction, and 5 minutes after each anastomosis (LAD, PD, $\mathrm{OM}$, and Dg). The last measurement was performed with the heart returned to its anatomical position. Postoperative lactate was also evaluated.

\section{Statistical Analysis}

Categorical data were presented in absolute (n) and relative (\%) frequencies. All hemodynamic data were expressed as the mean value \pm standard deviation. The Shapiro-Wilk test was applied to tested variables for normality distribution. Hemodynamic changes during the heart's displacement for each coronary anastomosis were compared using ANOVA for repeated measures. The drop in hemodynamic variables was presented by the difference between the initial or after the procedure value minus the during the heart's displacement value. A statistically significant level was considered when $P$-value $<0.05$. Statistical analyzes were carried out by GraphPrism 7.0 Software (GraphPad, USA). 


\section{RESULTS}

All patients were successfully operated on according to the scheduled protocol. Demographic data are listed in Table 1. No patient presented signs of intraoperative myocardial infarction, as assessed by abnormal elevation of serial cardiac enzymes or 12-lead ECG changes.

The mean number of anastomoses was 2.7 per patient and the left ventricular ejection fraction (LVEF) varied between 0.31 and 0.71 (mean 0.61 \pm 0.10 ); four patients had LVEF below 0.45 . There was no significant change in HR and MABP for all anastomoses, except for MABP during PD grafting $(-10.1 \pm 2.7$ $\mathrm{mmHg}, P=0.03$; Figure 2). The effects on $\mathrm{ScvO}_{2}$ were variable, but no change above $10 \%$ was observed. There was a significant decrease in $\mathrm{SCVO}_{2}$ only during PD and OM anastomoses (-9.4 \pm 0.4 , $P=0.03 ;-4.4 \pm 0.4, P=0.02$; respectively, Figure 2). CVP drop after PD manipulation was strongly associated with a higher lactate during the first hours after surgery $(r=-0.82 ; P=0.001)$. These hemodynamic changes were transient and entirely recovered after the heart was returned to its anatomical position.

No significant differences were observed in $\mathrm{FCl}$, SVV, or SVRI during all anastomoses, except for a drop in SVRI during PD grafting $(-8.03 \pm 2.3, P=0.007$; Figure 3$)$. SV tended to decrease during the procedure in all territories, but with statistically significant drop only in PD and OM grafting $(-10.4 \pm 1.2, P=0.02$; $-13.6 \pm 5.1, P=0.007$; respectively, Figure 3).
Table 1. Demographic, clinical, and operative data of participants.

\begin{tabular}{l|c}
\hline Variables & $\mathbf{n}=\mathbf{2 7}$ \\
\hline Age (years) & $63.7 \pm 9.6$ \\
\hline Male/Female $(\mathrm{n})$ & $16-11$ \\
\hline Body mass index $\left(\mathrm{kg} / \mathrm{m}^{2}\right)$ & $26.6 \pm 4.5$ \\
\hline Hypertension, $\mathrm{n}(\%)$ & $22(81.48)$ \\
\hline Diabetes, $\mathrm{n}(\%)$ & $12(44.44)$ \\
\hline Current smokers, $\mathrm{n}(\%)$ & $6(22.22)$ \\
\hline Previous Ml, $\mathrm{n}(\%)$ & $10(37.03)$ \\
\hline LVEF & $0.61 \pm 0.10$ \\
\hline$\beta$-blockers, $\mathrm{n}(\%)$ & $25(92.59)$ \\
\hline Nitrate, $\mathrm{n}(\%)$ & $11(40.74)$ \\
\hline Calcium channels blockers, $\mathrm{n}(\%)$ & $6(22.22)$ \\
\hline ACE inhibitors, $\mathrm{n}(\%)$ & $12(4.44)$ \\
\hline
\end{tabular}

Data are presented in mean \pm standard deviation.

$A C E=$ angiotensin converting enzyme; $\beta=$ blockers medication doses; $L V E F=$ left ventricular ejection fraction; $M I=$ myocardial infarction

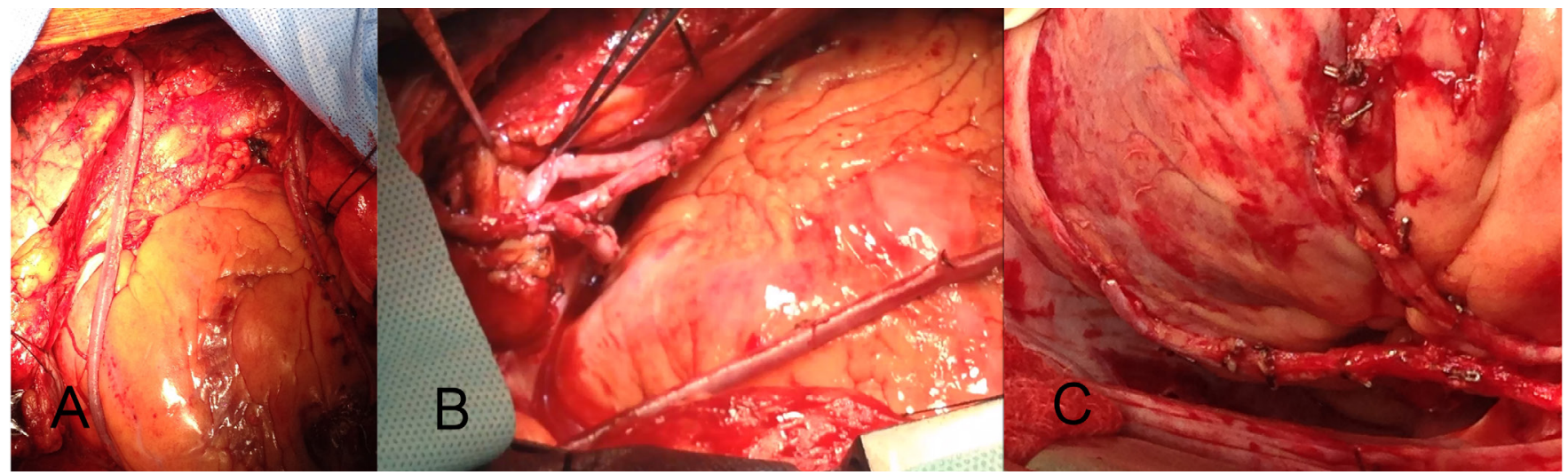

Fig 1 - A. The pericardium is not split over the aorta. Bilateral ITA grafts (LITA-LAD and RITA-OM in Y fashion) and vein graft to PDA anastomosed end-to-end with the RITA proximal stump). B. RITA and saphenous vein grafts anastomosed to LITA, in addition to RITA-vein-PDA. C. LITA sequential grafting to $L A D$ and $D g$ and RITA free graft to OM.

\section{DISCUSSION}

The main findings of this present study revealed that hemodynamic alterations during distal graft construction in aorta no-touch OPCAB were more commonly related to PD and OM anastomoses (inferior and lateral walls, respectively), but these were transient and well tolerated, with the heart fully recovering when it was returned to its anatomical place. The heart displacement for $L A D$ anastomosis is the least affected by hemodynamic changes, that is why it is performed first in the sequence. Moreover, early revascularization of the left ventricle (LV) anterior wall affords protection to the bulk of the LV myocardium, therefore allowing for safer heart displacement to accomplish the operation.
The hemodynamic compromise is an important concern with this technique, caused by displacement of the beating heart, which is vital for optimal exposure of the circumflex and PD artery. However, innovative improvements for coronary artery visualization ${ }^{[5,6]}$ and advanced methods for heart positioning and anastomotic site stabilization ${ }^{[7,8]}$ improved safety and technical quality, resulting in wider acceptance and extended use of this operation.

Coronary artery bypass grafting $(\mathrm{CABG})$ has consistently been demonstrated to be the most effective therapy for the treatment of patients with advanced obstructive atherosclerotic coronary artery disease, providing reduction of the long-term risk 
A

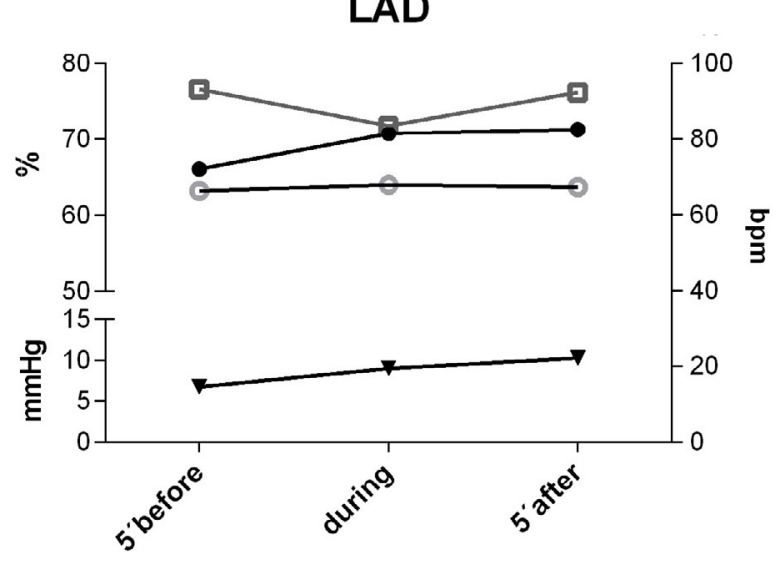

C

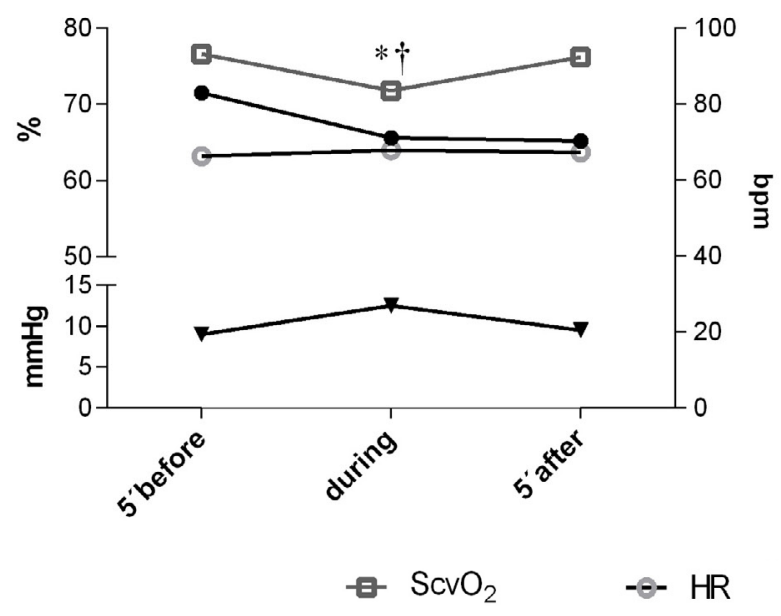

B

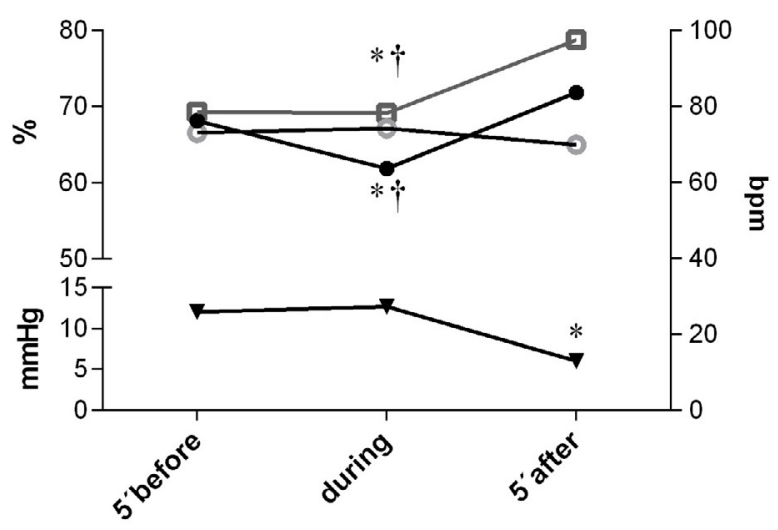

D

$\mathrm{Dg}$

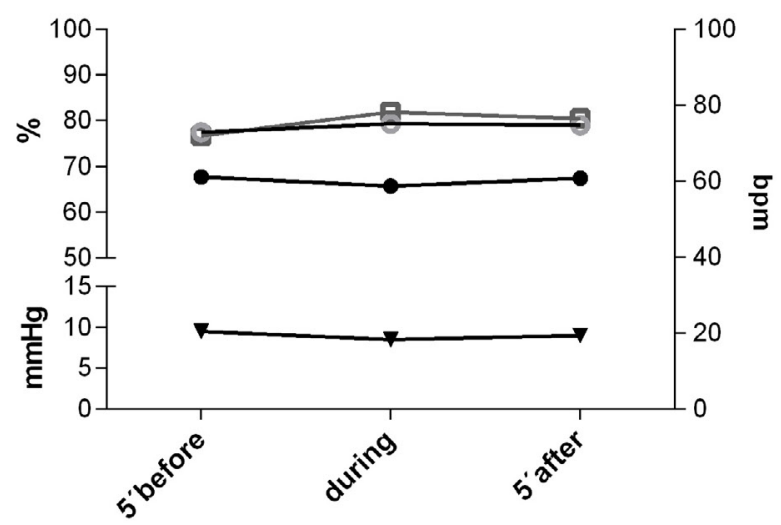

CVP

MABP

Fig. 2 - Hemodynamic changes during coronary artery bypass graft anastomosis.

$C V P=$ central venous pressure; $D g=$ diagonal; $H R=$ heart rate; $L A D=$ left anterior descending; $M A B P=$ mean arterial blood pressure; $O M=O b t u s e$ marginal; $P D=$ posterior descending; $\mathrm{SCVO}_{2}=$ central venous oxygen saturation

of death and myocardial infarction, compared to percutaneous coronary intervention $(\mathrm{PCl})^{[1]}$. However, the increased risk of stroke following CABG remains a major drawback for surgical revascularization compared with $\mathrm{PCl}$, which is mostly related to the aorta manipulation ${ }^{[9]}$.

Several meta-analyses revealed that OPCAB significantly reduces the incidence of postoperative neurological complications compared to on-pump $\mathrm{CABG}^{[10,11]}$, although an increased risk still persists owing to the need of ascending aorta clamping to construct the proximal anastomosis ${ }^{[12]}$.

More than 60 randomized trials so far have compared OPCAB with on-pump $C A B G$, allowing for construction of several metaanalyses of these trials, all coming to a similar conclusion: $O P C A B$ significantly reduced short-term rates of stroke and renal failure but did not reduce the risk of mortality or myocardial infarction in low and mixed risk patients. Specific studies targeting high-risk patients found a significant reduction in mortality with $O P C A B$ compared with on-pump CABG, although with higher rates of repeat revascularization ${ }^{[13]}$.

In the CORONARY trial[ ${ }^{[14]}$, the largest prospective randomized trial performed so far comparing on- and off-pump surgery, the rate of the composite outcome of death, stroke, myocardial infarction, renal failure, or repeat revascularization at 5-years follow-up was similar among patients who underwent $O P C A B$ and on-pump CABG.

Recent network meta-analysis demonstrated that avoidance of aortic manipulation in OPCAB may decrease the risk of postoperative stroke, especially in higher-risk patients. Additionally, the study pointed out that the elimination of cardiopulmonary bypass may reduce the risk of short-term mortality, renal failure, atrial fibrillation, bleeding, and length of intensive care unit stay ${ }^{[15]}$. Therefore, the aorta no-touch OPCAB means a step forward and a refinement of the outcomes provided by the earliest OPCAB technique. 
A

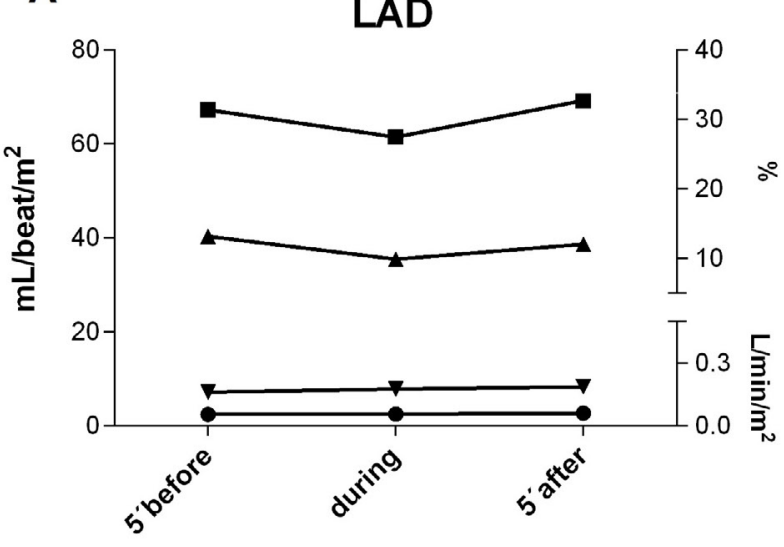

C

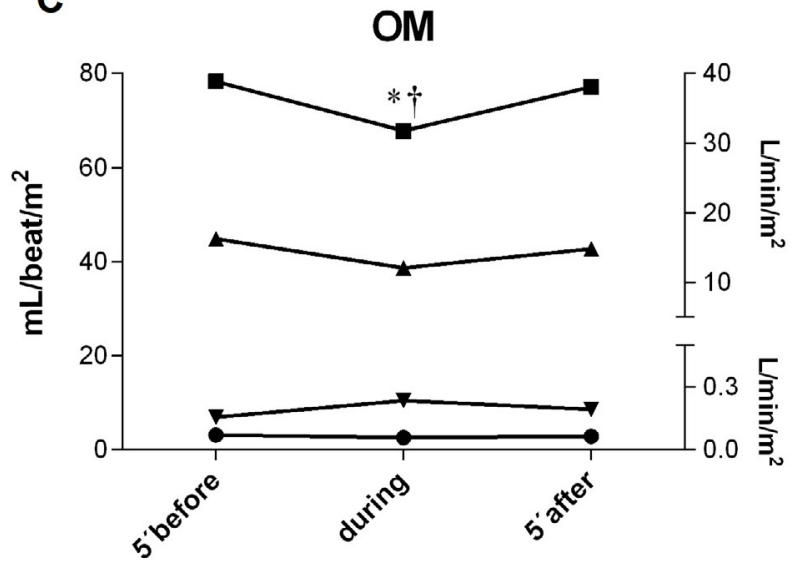

B

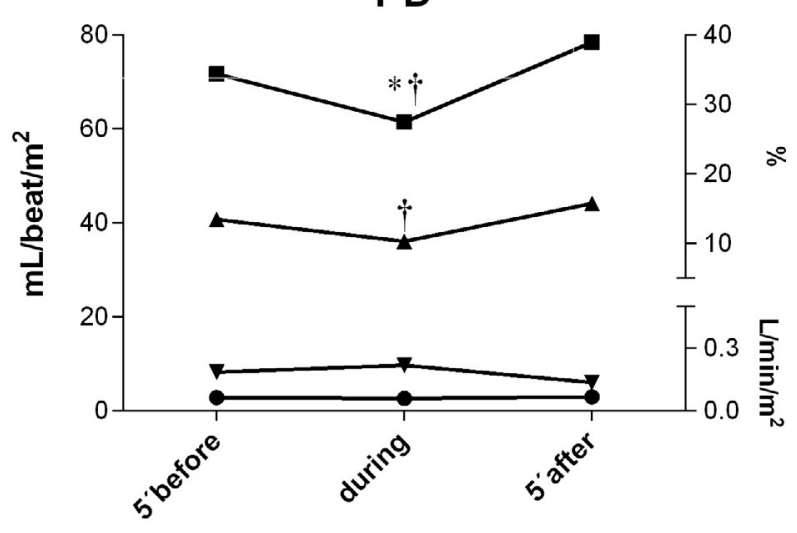

D

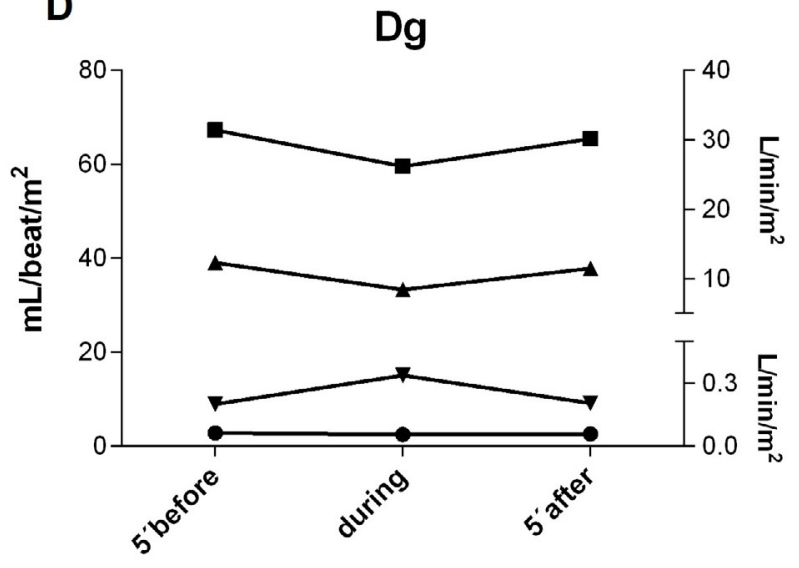

$\mathrm{FCl}$

Fig. 3 - Hemodynamic responses during coronary artery bypass graft anastomosis.

$D g=$ diagonal; $F C l=$ continuous cardiac index; $L A D=l e f t$ anterior descending; $O M=O b t u s e$ marginal; $P D=$ posterior descending; $S V=s t r o k e$ volume; $S V R I=$ systemic vascular resistance index; $S V V=$ stroke volume variation

In another seminal study, the no-aortic touch technique afforded the lowest risk for postoperative stroke in patients undergoing $C A B G$. Clamping the aorta during $C A B G$ increased the risk of postoperative stroke, regardless of the severity of aortic disease ${ }^{[16]}$. An additional strategy to overcome this pitfall, the technique for anastomosis of the top end of the vein graft to the proximal stump of RITA in the anaortic (aorta no-touch) OPCAB, has been developed and extensively employed in this case series ${ }^{[17]}$.

In Brazil, off-pump surgery has been demonstrated to reduce short-term costs of the procedure in $25 \%$ compared to the onpump CABG, as well as it is cost-effective in the 5-years followup comparative analysis of the MASS-III trial. In our country, with severe health budget constraints, this savings could increase the ability to care for patients by one quarter ${ }^{[18-20]}$.

OPCAB surgery has been questioned regarding its efficacy and safety in comparison to the conventional technique, especially with the outcomes related to incomplete revascularization and quality of grafts. However, the quality of anastomosis in off-pump surgery is directly related to the surgeon's experience. While experienced surgeons performing the technique reported the same degree of patency of the techniques over 8-years followup $^{[21,22]}$, in trials including less experienced surgeons, the OPCAB short- and long-term outcomes were inferior and led to high intraoperative conversion rates, as reported in the ROOBY tria|[23]. Similarly, experienced surgeons tend to achieve higher rates of complete revascularization in the OPCAB technique.

Based in these recent evidences, the aorta no-touch OPCAB has been the recommended technique for patients with cerebrovascular disease and/or calcification or atheromatous plaque in the ascending aorta. Furthermore, it should be favored in patients with high-risk factors such as old age, left ventricular impairment, and renal failure.

Worsening of cardiac function due to heart's dislodgement during $O P C A B$ can result in obstruction of the right ventricular outflow tract and failure in LV pumping mechanism. These changes elicit reduced $\mathrm{CO}$, hypotension, and myocardial ischemia, 
potentially leading to cardiac arrest and urgent need to onpump conversion. Then, likely benefits could be provided by real-time less invasive monitoring system allowing continuous determination of $\mathrm{CO}$ and other hemodynamic variables in $\mathrm{OPCAB}$, and letting promptly correction or earlier conversion to on-pump technique ${ }^{[24]}$. Postoperative complications and mortality are markedly higher in patients with hemodynamic instability who underwent a delayed switch to an on-pump CABG ${ }^{[24]}$.

The number of coronary artery anastomoses during $\mathrm{OPCAB}$ is increasing, more arterial grafts are being performed, and then the requirement of proper and accurate management of hemodynamic and metabolic parameters during coronary anastomosis emerges. Apart from intravenous fluid loading and head-down (Trendelenburg) position to compensate the drop of mean arterial pressure and $\mathrm{CO}$, the use of a combination of inotropic drugs should be more intensively evaluated in this setting. Particularly, $\mathrm{ScvO}_{2}$ reflects hemodynamic changes earlier compared to the CO measured every 60 seconds and it has critical significance since it represents both delivery and consumption of oxygen. Although measurement of the $\mathrm{CO}$ level is too slow for monitoring the cardiac status during the manipulation and tilting of the heart, the $\mathrm{CO}$ is still useful as a trend monitor during the entire surgical period. Ultimately, the hemodynamic changes during OPCAB are also heavily dependent on the surgical technique, surgeon's skill, and the operative team's experience.

In recent years, the FloTrac/Presep/Nigileo ${ }^{\mathrm{TM}}$ has been introduced into clinical practice, establishing a new concept of a semi-invasive device based on arterial waveform analysis for $\mathrm{FCl}$ evaluation and $\mathrm{ScvO}_{2}$ monitoring, along with patient's anthropometric data, skipping the necessity of calibration by thermodilution. Broch et al. ${ }^{[25]}$ comparatively evaluated the accuracy of $\mathrm{FCl}$ determination based on arterial waveform analysis with transpulmonary thermodilution in patients scheduled for elective $C A B G$, showing a moderate, but significant correlation between pulse contour $\mathrm{FCl}$ and thermodilution $\mathrm{FCl}$, both before and after cardiopulmonary bypass. Not only the uncalibrated semi-invasive monitoring system was capable to reliably measure $\mathrm{FCl}$ compared with transpulmonary thermodilution in patients undergoing elective $C A B G$, but additionally the semiinvasive monitoring device was able to detect hemodynamic changes and trends.

Yet, Jo et al. ${ }^{[26]}$ compared the $\mathrm{FCl}$ measured by the FloTrac/ Vigileo ${ }^{\mathrm{TM}}$ system to that obtained by a pulmonary artery catheter in patients with decreased LVEF and low CO status during OPCAB. The $\mathrm{FCl}$ was reliable at all points of measurement and the authors concluded that the CO measured by the FloTrac/Vigileo ${ }^{\mathrm{TM}}$ system was consistent in patients with decreased LVEF and low CO status during $O P C A B$, even during the period of heart's displacement and OM grafting ${ }^{[26]}$. Conversely, other studies reported lower accuracy of uncalibrated arterial waveform analysis of SV to predict fluid responsiveness in patients with impaired LVEF and low $\mathrm{CO}$, especially those with $\mathrm{FCl}<2.2 \mathrm{~L} / \mathrm{min} / \mathrm{m}^{2[27,28]}$.

The routine use of continuous cardiac output (CCO) and $\mathrm{ScvO}_{2}$ monitoring for OPCAB is still a matter of debate, related to the question of whether increasing the degree and complexity of invasive monitoring will lead to improved outcomes. These devices may provide valuable information from a trending viewpoint, which may be useful for hemodynamic management in intra- and postoperative period. Accurate and timely data regarding these endpoints may signify the difference between carry-on the case off-pump or urgently convert it to on-pump surgery ${ }^{[29]}$ In this case series, no premonitory changes that could trigger an alarm for shifting the operative strategy were detected and that might be related to the number of patients included, so further increasing the caseload may be of help in elucidating this question.

\section{CONCLUSION}

The heart displacement for performing aorta no-touch OPCAB in all main coronary arteries is well tolerated, with transient and endurable hemodynamic variations and no substantial influence on metabolic parameters or adverse clinical events. Close monitoring using the FloTrac/PreSep/Nigileo ${ }^{\text {TM }}$ system may be valuable for prompt identification of significant hemodynamic and metabolic changes and implementation of proper intervention at the time of coronary artery anastomosis in patients undergoing aorta no-touch OPCAB.

\section{Authors' roles \& responsibilities}

ARC Substantial contributions to the conception or design of the work; or the acquisition, analysis, or interpretation of data for the work; final approval of the version to be published

SG Substantial contributions to the conception or design of the work; or the acquisition, analysis, or interpretation of data for the work; final approval of the version to be published

GMM Final approval of the version to be published

IB Drafting the work or revising it critically for important intellectual content; final approval of the version to be published

ISR Drafting the work or revising it critically for important intellectual content; final approval of the version to be published

NAHJ Final approval of the version to be published

EGC Drafting the work or revising it critically for important intellectual content; final approval of the version to be published

JMTS Drafting the work or revising it critically for important intellectual content; final approval of the version to be published

RAM Drafting the work or revising it critically for important intellectual content; final approval of the version to be published

GCOL Final approval of the version to be published

ACN Final approval of the version to be published

CERS Final approval of the version to be published

JPMF Final approval of the version to be published

WJG Substantial contributions to the conception or design of the work; or the acquisition, analysis, or interpretation of data for the work; final approval of the version to be published 


\section{REFERENCES}

1. Windecker S, Kolh P, Alfonso F, Collet JP, Cremer J, FalkV, et al. 2014 ESC/ EACTS Guidelines on myocardial revascularization: The Task Force on Myocardial Revascularization of the European Society of Cardiology (ESC) and the European Association for Cardio-Thoracic Surgery (EACTS) Developed with the special contribution of the European Association of Percutaneous Cardiovascular Interventions (EAPCI). Eur Heart J. 2014;35(37):2541-619.

2. Zhao DF, Edelman JJ, Seco M, Bannon PG, Wilson MK, Byrom MJ, et al. Coronary artery bypass grafting with and without manipulation of the ascending aorta: a network meta-analysis. J Am Coll Cardiol. 2017;69(8):924-36.

3. Keeling B, Thourani V, Aliawadi G, Kim S, Cyr D, Badhwar V, et al. Conversion from off-pump coronary artery bypass grafting to on-pump coronary artery bypass grafting. Ann Thorac Surg. 2017;104(4):1267-74.

4. Senn A, Button D, Zollinger A, Hofer CK. Assessment of cardiac output changes using a modified FloTrac/Vigileo algorithm in cardiac surgery patients. Crit Care. 2009;13(2):R32.

5. Gomes WJ, Buffolo E. A simple device for visualization in off-pump coronary artery bypass surgery. Ann Thorac Surg. 2005;80(4):1567.

6. Sellke FW, Chu LM, Cohn WE. Current state of surgical myocardial revascularization. Circ J. 2010;74(6):1031-7.

7. Nathoe HM, van Dijk D, Jansen EW, Suyker WJ, Diephuis JC, van Boven WJ, et al. A comparison of on-pump and off-pump coronary bypass surgery in low-risk patients. N Engl J Med. 2003;348(5):394-402.

8. Detter C, Deuse T, Christ F, Boehm DH, Reichenspurner H, Reichart B. Comparison of two stabilizer concepts for off-pump coronary artery bypass grafting. Ann Thorac Surg. 2002;74(2):497-501.

9. Smit $Y$, Vlayen J, Koppenaal H, Eefting F, Kappetein AP, Mariani MA. Percutaneous coronary intervention versus coronary artery bypass grafting: a meta-analysis. J Thorac Cardiovasc Surg. 2015;149(3):831-8.e1-13.

10. Wang J, Gu C, Gao M, Yu W, Li H, Zhang F, et al. Comparison of the incidence of postoperative neurologic complications after on-pump versus off-pump coronary artery bypass grafting in high-risk patients: a meta-analysis of 11 studies. Int J Cardiol. 2015;185:195-7.

11. Sá MPBO, Ferraz PE, Escobar RR, Martins WN, Lustosa PC, Nunes EO, et al. Off-pump versus on-pump coronary artery bypass surgery: metaanalysis and meta-regression of 13,524 patients from randomized trials. Rev Bras Cir Cardiovasc. 2012;27(4):631-41.

12. Misfeld M, Brereton RJ, Sweetman EA, Doig GS. Neurologic complications after off-pump coronary artery bypass grafting with and without aortic manipulation: meta-analysis of 11,398 cases from 8 studies. J Thorac Cardiovasc Surg. 2011;142(2):e11-7.

13. Head SJ, Milojevic M, Taggart DP, Puskas JD. Current practice of state-of-the-art surgical coronary revascularization. Circulation. 2017;136(14):1331-45.

14. Lamy A, Devereaux PJ, Prabhakaran D, Taggart DP, Hu S, Straka Z, et al. Five-year outcomes after off-pump or on-pump coronary-artery bypass grafting. N Engl J Med. 2016;375(24):2359-68.

15. Zhao DF, Edelman JJ, Seco M, Bannon PG, Wilson MK, Byrom MJ, et al. Coronary artery bypass grafting with and without manipulation of the ascending aorta: a network meta-analysis. J Am Coll Cardiol. 2017;69(8):924-36.
16. Moss E, Puskas JD, Thourani VH, Kilgo P, Chen EP, Leshnower BG, et al. Avoiding aortic clamping during coronary artery bypass grafting reduces postoperative stroke. J Thorac Cardiovasc Surg. 2015;149(1):175-80.

17. Gomes WJ, Pereira FA, Hossne Jr HA, Carvalho AR, Dias TL, Matsue JK, et al. The technique of anastomosis of saphenous vein graft with the proximal segment of the right internal thoracic artery in the aorta notouch off-pump coronary artery bypass surgery. Paper presented at the 45th Congress of the Brazilian Society of Cardiovascular Surgery, Goiania GO, Brazil, April 19-21, 2018.

18. Girardi P, Hueb W, Nogueira CR, Takiuti M, Nakano T, Garzillo CL, et al. Comparative costs between myocardial revascularization with or without extracorporeal circulation. Arq Bras Cardiol. 2008;91 (6):340-6.

19. Gomes WJ, Braile DM. On-pump versus off-pump coronary artery bypass surgery: the impact on costs of health care systems. Arq Bras Cardiol. 2008;91(6):338-9.

20. Scudeler TL. Custo-efetividade da cirurgia de revascularização miocárdica com e sem circulação extracorpórea em pacientes portadores de doença coronariana multiarterial estável. Resultados do estudo MASS-III [Tese de doutorado]. São Paulo: Faculdade de Medicina da Universidade de São Paulo; 2018.

21. Puskas JD, Williams WH, Mahoney EM, Huber PR, Block PC, Duke PG, et al. Off-pump vs conventional coronary artery bypass grafting: early and 1-year graft patency, cost, and quality-of-life outcomes: a randomized trial. JAMA. 2004;291(15):1841-9.

22. Angelini GD, Culliford L, Smith DK, Hamilton MC, Murphy GJ, Ascione $\mathrm{R}$, et al. Effects of on- and off-pump coronary artery surgery on graft patency, survival, and health-related quality of life: Iong-term follow-up of 2 randomized controlled trials. JThorac Cardiovasc Surg. 2009;137(2):295-303.

23. Shroyer AL, Grover FL, Hattler B, Collins JF, McDonald GO, Kozora E, et al. On-pump versus off-pump coronary-artery bypass surgery. N Engl J Med. 2009;361(19):1827-37.

24. Yoon SS, Bang JH, Jeong SS, Jeong JH, Woo JS. Risk factors of on-pump conversion during off-pump coronary artery bypass graft. Korean J Thorac Cardiovasc Surg. 2017;50(5):355-62.

25. Broch O, Renner J, Gruenewald M, Meybohm P, Schöttler J, Steinfath M, et al. A comparison of third-generation semi-invasive arterial waveform analysis with thermodilution in patients undergoing coronary surgery. Scientific World J. 2012;2012:451081

26. Jo YY, Song JW, Yoo YC, Park JY, Shim JK, Kwak YL. The uncalibrated pulse contour cardiac output during off-pump coronary bypass surgery: performance in patients with a low cardiac output status and a reduced left ventricular function. Korean J Anesthesiol. 2011;60(4):237-43.

27. Montenij LJ, Sonneveld JP, Nierich AP, Buhre WF, De Waal EE. Accuracy, precision, and trending ability of uncalibrated arterial pressure waveform analysis of cardiac output in patients with impaired left ventricular function: a prospective, observational study. J Cardiothorac Vasc Anesth. 2016;30(1):115-21.

28. Maeda T, Yoshitani K, Inatomi Y, Ohnishi Y. Inaccuracy of the FloTrac/ Vigileo $^{\mathrm{TM}}$ system in patients with low cardiac index. J Cardiothorac Vasc Anesth. 2014;28(6):1521-6.

29. Birmingham S, Nguyen L, Banks D. Con: continuous cardiac output and $\mathrm{SvO}_{2}$ monitoring are not routine in off-pump coronary artery bypass grafting. J Cardiothorac Vasc Anesth. 2012;26(6):1136-8. 